s

\section{Research Square}

\title{
Incidence and associated factors of laryngospasm among pediatric patients who undergone surgery under general anesthesia, in university of Gondar Compressive Specialized Hospital, Northwest Ethiopia, 2019: Cross sectional study
}

Wubie Birlie Chekol ( $\sim$ birliewubie@gmail.com )

University of Gondar

Debas Yaregal Melese

University of Gondar

\section{Research note}

Keywords: laryngospasm; pediatric anesthesia; general anesthesia

Posted Date: October 23rd, 2019

DOI: https://doi.org/10.21203/rs.2.14692/v2

License: (c) (1) This work is licensed under a Creative Commons Attribution 4.0 International License. Read Full License 


\section{Abstract}

Objective: laryngospasm is a glotiss closure due to reflex constriction of the laryngeal muscles. It mainly happened at induction, maintenance and emergence phases of general anaesthesia (GA).Considerable research have been done previously but, consequences of laryngospasm, various results and gate opener values of previous studies intiated us to do this research. So this study was aimed to assess the incidence and associated factors of laryngospasm among pediatric patients who undergone surgery under GA.

Methods:institutional based cross sectional study was conducted on pediatric patients from February to August, 2019 in university of Gondar comprehensive specialised hospital (UOGCSH). Data were entered and analaysed with SPSS version 20.Variables with $P$ value less than 0.2 in bivariate analysis was fitted in to multivariable logistic regression analysis to identify factors associated with laryngospasm. Both crude and adjusted odds ratio with $95 \% \mathrm{Cl}$ were calculated to show the strength of association. In multivariable analysis, P value of less than 0.05 were considered as statistically significant.

Results: The incidence of laryngospasm among pediatric patients who undergone surgery under GA was 57 (18.39\%) . Of this 34 (59.6\%) were happened during emergence, 12 (21.1\%) during maintenance and $11(19.3 \%)$ during induction phase of GA. In multivariable analysis, airway anomalies (AOR : $14.64,95 \% \mathrm{Cl}: 1.71,125.04)$, orophyrangeal secretion (AOR : $2.45,95 \% \mathrm{Cl}: 1.19,5.06)$, attempts of airway devices insertion (AOR : $2.47,95 \% \mathrm{Cl}: 1.16,5.22)$, upper respiratory tract infection (AOR : 2.91,95\% Cl:1.008,8.41) and inadequate depth of anesthesia (AOR : 7.92,95\%Cl:2.7,23.22) were significantly associated with incidence of laryngospasm.

Conclusion: laryngospasm at induction, maintainance and emergence phases of GA was high in UOGCSH. Inadequate depth of anaesthesia, upper respiratory tract infection, airway anomalies, multiple attempts of airway device insertion, and orophyrangeal secretion were predictors of laryngospasm. So it is better to have patient optimisation for patients having URTI and airway anomalies, reduce the attempts of airway device insertion and adequate depth of anesthesia as well as adequate suctioning of oropharynx.

\section{Background}

Pediatric laryngospasm is an anesthetic emergency which can be defined as glottis closure due to reflex constriction of the laryngeal muscles that produces partial or complete obstruction of the larynx. It mainly happen during induction,maintainance and emergence phases of GA[1].Laryngospasm usually manifests with the sign of inspiratory stridor which may progress to complete obstruction, increased respiratory effort, tracheal tug, paradoxical respiratory effort, oxygen desaturation with or without bradycardia and airway obstruction which does not respond to a Guedel airway [2].

The reported incidence of laryngospasm was differing in different studies. Laryngospasm more commonly happened in pediatric anesthetic practices than adults. The overall incidence of laryngospasm was $0.87 \%$ in adults, $1.7 \%$ in pediatrics and $2.82 \%$ in infants. The incidence of laryngospasm in older children was twice that of adults, while the incidence of laryngspasm in younger children was three times that of adults [3-5].According to haile et al report the incidence of laryngospasm on pediatric patients who underwent surgery under GA was $28.3 \%$ [6].Another study reported the incidence of laryngospasm as $10 \%$ in the very young pediatric patient with reactive airways, either due to upper respiratory infection or asthma. The incidence of laryngospasm has been reported in the literature as high as $25 \%$ in patients undergoing tonsillectomy and adenoidectomy [7].

The main triggering factors for laryngospasm were inappropriate depth of anesthesia, suction catheter, thiopentone ,inhalational induced irritation, secretion, stimulation of the airway, tracheal intubation[8], airway anomalies and upper respiratory tract infection $[9,10]$;Surgical factors including tonsillectomy,adenoidectomy,appendiectomy, dialatation of the anus and thyroidectomy[11-13]. 
If laryngospasm persists it may causes to hypoxia and hypercapnea.In rare situations, serious morbidity and mortality of hypoxia and hypercapnia may leads to arrhythmia, aspiration of gastric content, bronchospasm and cardiac arrest $[1,14]$.

According to haile et al study laryngospasm was managed by stimulus removal, continuous positive airway pressure(CPAP) with $100 \%$ oxygen, jaw thrust and increasing the depth of anesthesia for partial laryngospasm and administration of intravenous suxamethonium for complete laryngospasm [6].

The quality of anesthesia gets improved through time but, still we had personal observations about the incidence of laryngospasm in pediatrics population. Also, several adverse respiratory features were encountered in concomitant with laryngospasm.Although, considerable research have been done previously the consequences of laryngospasm, varied results on previous studies and gate opener values of previous studies initiated us to do this research. So, this study was done to determine the incidence and associated factors of laryngospasm in pediatric patients who undergone surgery under GA at University of Gondar Comprehensive Specialized Hospital (UOGCSH).

\section{Methods}

\section{Study design, period and study settings}

Institutional based cross-sectional study was conducted on pediatric patients that undergone surgery under GA in UOGCSH from February 1 to August 1, 2019.This hospital is located in Amhara region, North Gondar zone, which is about 738km away from Addis Ababa in Northwest of Ethiopia.

\section{Study population}

All consecutive pediatric patients (birth-12 years) that operated in both emergency and elective conditions with GA at the main and ophthalmic operation theatres during the study period were included.

\section{Variables of the study}

The outcome variable was incidence of laryngospasm. The independent variables were socio-demographic factors (age, sex, ASA status), patient factors (current history of URTI, co- morbidities, pre existing airway anomalies, history of exposure to smoke inhalation), anesthetic factors (types of anesthesia, use of oral airway devices, types of induction, induction drugs, maintenance drugs, multiple attempts of airway device insertion, inadequate depth of anesthesia, secretion at oropharynx) and surgical factors (types of surgery, urgency of surgery).

\section{Operational definitions}

Laryngospasm:glotic closure due to reflex constriction of the laryngeal muscles that produces partial or complete obstruction of the larynx that manifested either alone or in combination of inspiratory stridor, increased respiratory effort, tracheal tug, paradoxical respiratory effort,desaturation and bradycardia[2].

Signs of inadequate depth anesthesia: when patients were manifested with either movements, increased breathing, increased heart rate and increased blood pressure in response to stress or painful stimuli[15].

Multi-attempts of airway device: means if there were $\geq 2$ attempts in securing of the airway[16]

\section{Sample size determination}

The sample size was determined by using single proportion formula $\left(\mathrm{N}=\frac{\left((\mathrm{z} / 2)^{2} \mathrm{xpq}\right.}{d^{2}}\right)$ with a 
study done in Jimma University specialized and teaching hospital (2015), Southwest Ethiopia, which reported that the incidence of laryngospasm was $28.3 \%[6]$. By assuming $95 \%$ confidence level, $5 \%$ margin of error and $5 \%$ none response rate, Where; $\mathrm{N}=$ Sample size, $\mathrm{P}=$ Percentage $, \mathrm{Q}=1-\mathrm{P}, \mathrm{D}=$ Desired degree of precision, $\mathrm{Z}=$ the standard normal value at the level of confidence desired. $\mathrm{N}=(1.96)^{2}(0.72)(0.28) /(.05)^{2}=309$. When $5 \%$ of the non- response rate was added, the total number of patients who participated in the study was $\mathrm{N}=325$.

\section{Data management and collection procedures}

Training was given for data collectors and supervisors. The training was focused on each item of the study tool, relevance of the study and how to ensure confidentiality of patient's data.The data collection procedures were including consent from the parents, reviewing of the chart, interviewing of the parents, recording of anesthetic factors, surgical factors, interventions done for cases and laryngospasm incidence at induction, maintenance and emergence phases of GA. During data collection regular supervision and follow up were done for the completeness, accuracy and clarity of data.

\section{Data analysis and interpretation}

SPSS version 20 was used for data entry and analysis. Both bivariate and multivariate binary logistic regression analysis were used to identify factors associated with laryngospasm. Variables with a p-value less than $<0.2$ in the bivariate analysis were fitted into the multivariable logistic regression analysis. Both crude and adjusted odds ratio with the corresponding $95 \% \mathrm{Cl}$ were calculated to show the strength of association. Hosmer and Lemeshow test was used to assess the goodness of fit. In multivariable analysis, variables with a p-value of $<0.05$ were considered as statistically significant. Categorical variables were analyzed with chi-square test and presented with frequency (percent).Tables and graphs were used for presentation of descriptive data.

\section{Ethical consideration}

Ethical clearance was obtained from ethical review board of school of medicine at University of Gondar. Informed consent was obtained from the parents. Brief explanation for parents was done about the risks and benefits in study participation. Confidentiality and anonymity was ensured.

\section{Results}

\section{Socio-demographic and patient related variables}

Total of 310 patients were included in this study with $95.4 \%$ response rate. Fifteen patients were excluded from analysis due to the incomplete data. The study involved 177 (55.2\%) male and 139 (44.8) female participants with age range from birth to 12 years. Majority of study participants 238 (76.8\%) were ASA 1; while the remaining $56(18.1 \%)$ and 16 (5.1\%) were ASA 2 and ASA 3 respectively. In this study 9 (2.9\%) of the study participants were having airway anomalies, $13(4.2 \%)$ of patients were having respiratory co morbidities and $33(10.64 \%)$ of patients were having URTI.

\section{Surgical and anesthetic related variables}

Majority of patients 195 (62.9\%) were operated under GA with ETT.The commonly done procedures in this study were abdominal 103 (33.2\%), ophthalmic 67 (21.6\%), orthopedic 50 (16.1\%) and ENT 44 (14.2\%) procedures (Table 1).

\section{Anesthetic related variables}

Majority of the study participants $270(87.1 \%)$ were induced with intravenous anesthetic agents. On the other hand greater part of them 210(67.7\%) were maintained with halothane (Table 2). 
In this study pediatric patients who operated under GA with having URTI was about 2.91 times (AOR: 2.91, 95\%Cl: 1.008, 8.41) more likely to had laryngospasm when compared with no URTI. Having of airway anomalies at preoperative assessment were 14.6 times (AOR: $14.64,95 \% \mathrm{Cl}: 1.71,125.04$ ) more likely to had laryngospasm than those who were not having airway anomalies. Similarly, those patients who had the signs of inadequate depth of anesthesia was 7.92 times (AOR: 7.92, 95\% Cl: 2.70, 23.22) more likely to develop laryngospasm than no manifestations (Table 3).

\section{Incidence of laryngospasm}

The overall incidence of laryngospasm was reported as 57 (18.39\%). Of the total incidence of laryngospasm 34 (59.6\%), 12 (21.1\%), 11 (19.3\%) were happened during emergence, maintainance and induction phases of GA respectively.

\section{Complications after laryngospasm}

Among the 57 (18.39\%) laryngospasm events, desaturation occurred in 56 (98.3\%), bradycardia occurred 54 (94.8\%), decreased air entry occurred in 46 (80.7\%), increased inspiratory effort occurred in 20 (35.1\%), paradoxical breathing occurred in $22(38.6 \%)$ and cyanosis occurred in 7 (12.3\%) of laryngospasm cases.

\section{Management for laryngospasm}

Among the 57 (18.39\%) laryngospasm events, the spasm was broken with removing the offending stimulus and administration of CPAP with $100 \%$ oxygen for 37 (64.9\%) of events, increased the depth of anesthesia for 7 (12.3\%) events and administration of suxamethonium for 5 (8.8) of laryngospasm events.

\section{Discussion}

This study was conducted to found out the incidence and associated factors of laryngospasm at induction, maintenance and emergence phases of GA.The overall incidence of laryngospasm was 57(18.39\%).The incidence of this study was slightly lower than a study done by Haile et al (28.3\%); However it was still higher than studies done by Orestes et al (1.6\%),Peng et al (12.5\% with LMA,9.5\% with ETT) and Al-Metawalli et al (8\%)[17-19].The discrepancies could be due to the modern refinements in anesthesia, surgical techniques and specificity of the procedures in the previous studies.

Of the overall incidence 34 (59.6\%), 12 (21.1\%) and 11 (19.3\%) were happened during emergence, maintenances and induction phases of GA respectively. Haile et al found out that the overall incidence of laryngospasm was 53 (28.3\%), of which 30 (56.6\%) happened during induction, 4(7.6\%) during maintenance and 19(35.8\%) happened during emergence phases of GA[6]. The possible explanation for the high incidence of laryngospasm during emergence in our study might be due to the high percentage of patients operated under GA with ETT 195(62.9\%). This suggestion was supported by a study done by visvanathan et al who found that the incidence of laryngospasm occurred more on induction phase if patient was on LMA and high during emergence if patient was on ETT[20].

Regarding to the associated factors, having URTI in pediatric surgical patients who operated under GA was about 2.91 times (AOR: 2.91, 95\%Cl:1.008,8.41) more likely to had laryngospasm when compared with no URTI.This study was supported by studies done in different settings reporting that there were statistically significant association between URTI and laryngospasm among pediatric patients who operated under $\mathrm{GA}[5,21-26]$. However ,prospective studies have failed to conclusively demonstrate an association between laryngospasm and URTI[27, 28].

Having of airway anomalies at preoperative assessment were 14.6 times (AOR: $14.64,95 \% \mathrm{Cl}$ : 1.71, 125.04) more likely to had laryngospasm than those who were not having airway anomalies. This finding was in line with other studies done by Flick et al,Fick et al and Cohen et al[23, 26, 29].

This study verified that intravenous anesthetic induction were used as protective agents for laryngospasm when compared with those induced with inhalational anesthetic agents(AOR: $0.31,95 \% \mathrm{Cl}: 0.12,0.78)$.In agreement with this study different 
literatures reported that propofol had less risky of laryngospasm due to the ability of blunting the airway reflexes and ketamine had no laryngospasm effect unless the increased tendency of secretion. However,inhalational anesthetic agents including desflurane and isoflurane were having higher incidences of laryngospasm in pediatric age groups[8, 30, 31].

Having the signs of inadequate depth of anesthesia was 7.92 times (AOR: 7.92, 95\%Cl: 2.70, 23.22) more likely to develop laryngospasm than no manifestations. In congruent with this, a study done by Aaalami et al confirmed that inadequate depth of anesthesia had a significant effect on the incidence of laryngospasm[5, 32].

Those pediatric patients who had secretion at the oropharynx were 2.45 times (AOR: $2.45,95 \% \mathrm{Cl}: 1.19,5.06)$ more likely to develop laryngospasm than who had no secretion at the oral cavity. This finding was supported by Olsson et al study[5].

Attempting of multiple times during airway devices insertion were 2.47 times (AOR: $2.47,95 \% \mathrm{Cl}: 1.16,5.22)$ more likely to develop laryngospasm than no multiple attempts. In matching with this finding Fick et al and Hernandez et al were identified the association between multiple attempts of airway devices insertion and laryngospasm[29, 33].

\section{Limitations}

- The diagnosis of laryngospasm was only depends on the clinical signs.

- There was no specification whether the laryngospasm is partial or complete.

\section{Abbreviations}

ASA - American society of anesthesiologists.

AOR - adjusted odds ratio.

Cl- confidence interval.

CPAP - continuous positive airway pressure.

UOGCSH - University of Gondar comprehensive specialized hospital.

URTI- upper respiratory tract infection.

ENT-(ear, nose, throat).

ETT-endotracheal tube.

LMA-laryngeal mask airway.

GA-general anesthesia.

\section{Declarations}

Ethics approval and consent to participate-"not applicable."

Consent to publish-"not applicable."

Availability of data and materials-the data sets used and analyzed during the study are available from the corresponding author on reasonable request.

Competing interest-we the authors did not have any competing financial or personal relationships that could be viewed as influential for the work of this paper. 
Funding-“not applicable.”

Author's contributions- W.B.C involved in conception and design of the study, acquisition of the data, analysis and interpretation of data, drafting of the manuscript and approval of the version of the manuscript to be published.D.Y.M was involved in data acquisition, revising of the manuscript critically for important intellectual content and approval of the version of the manuscript to be published.

Acknowledgements- we would like to acknowledge University of Gondar comprehensive specialized hospital for the chance of giving us to do this research. Also, we would like to acknowledge all the study team (for their directives and invaluable comments) and all data collectors for their unreserved efforts during data collection procedures.

\section{References}

1. Al-alami, A.A., M.M. Zestos, and A.S. Baraka, Pediatric laryngospasm: prevention and treatment. Current Opinion in Anesthesiology, 2009. 22(3): p. 388-395.

2. Gil, G. and W.R. WM, Laryngospasm in anaesthesia. Continuing Education in Anaesthesia, Critical Care \& Pain, 2014. 14 (2): p. 47-51.

3. Black AE. Laryngospasm in pediatric practice. Pediatr Anesth. 2008;18:279.

4. Holzki J. Laryngospasm. Pediatr Anesth. 2008;18:1144-6.

5. Olsson GL, Hallen B. Laryngospasm during anaesthesia. A computer-aided incidence study in 136929 patients. Acta Anaesthesiol Scand, 1984;28:567-75.

6. Haile M, Legesse S, Miressa S, Desalegn N (2015) Magnitude and Associated Risk Factors of Perioperative Pediatrics Laryngospasm under General Anesthesia. InternMed 5: 203. doi:10.4172/2165-8048.1000203.

7. Gulhas N, Durmus N, Demirbileks $S$ et al. The use of magnesium to prevent laryngospasm after tonsillectomy and adenoidectomy: a preliminary study. Paediatr Anaesth 2003; 13: 43-7.

8. Horita A, Dille JK. Observation on the action of thiopental on the laryngeal reflex. Anesthesiology. 1955;16:848-53.

9. Murat I, Constant I, Maud'huy H. Perioperative anaesthetic morbidity in children: a database of 24.165 anaesthetics over a 30-month period. Pediatr Anesth. 2004;14:158-66.

10. Flick RP, Wilder RT, Pieper SF, Van Koeverde K, Ellison KM, Marienau MES, et al. Risk factors for laryngospasm in children during general anesthesia. Pediatr Anesth. 2008;18:289-96.

11. Talmage, D. and Egan, Miller's Anesthesia, 6th Edition. Anesthesiology 2005,. 103(673).

12. Mortero RF, Orahovac Z, Tsueda K, et al. Severe laryngospasm at tracheal extubation in a patient with superior laryngeal nerve injury. Anesth Analg.2001;92:271-2.

13. Bauman NM, Sandler AD, Schmidt C, et al. Reflex laryngospasm induced by stimulation of distal afferents. Laryngoscope. 1994;104:209-14.

14. HAMPSON-EVANS, D., P. Morgan, and M. Farrar, Pediatric laryngospasm. Pediatric Anesthesia, 2008. 18(4): p. $303-307$.

15. S, A.M., M.G. A, and G.D. B, Prevention of awareness during general anesthesia. Med Rep, 2009. 1(9).

16. Goto, T. and K. Gibo, Multiple failed intubation attempts are associated with decreased sucess rates on the first rescue intubation in the emergency departement:a retrospective analysis of multicentre observational data. Scand J Trauma Resusc Emerg Med, 2015. 23(5).

17. Orestes, M.I., et al., Incidence of Laryngospasm and Bronchospasm in Pediatric Adenotonsillectomy. Laryngoscope, 2012. 122: p. 425-428.

18. Al-Metwalli RR, Mowafi HA, Ismail SA. Gentle chest compression relieves extubation laryngospasm in children. J Anesth 2010;24:854-857. 
19. Peng A, Dodson KM, Thacker LR, Kierce J, Shapiro J, Baldassari CM. Use of laryngeal mask airway in pediatric adenotonsillectomy. Arch Otolaryngol Head Neck Surg 2011;137:42-46.

20. Visvanathan T, Kluger MT, Webb RK et al. Crisis management during anaesthesia:laryngospasm. Qual Saf Health Care. 2005;14:e3.

21. Von Ungern BS, Boda K, Chambers NA, et al. Risk assessment for respiratory complications in pediatric anaesthesia: A prospective cohort study. Lancet. 2010;376(9743):773-783.

22. VON UNGERN-STERNBERG BS, Habre W. Pediatric anesthesia-potential risks and their assessment: part I. Pediatric Anesthesia. 2007;17(3):206-15.

23. Cohen MM, Cameron CB, Duncan PG. Pediatric anesthesia morbidity and mortality in the perioperative period. Anesthesia \& Analgesia. 1990;70(2):160-7.

24. Tait AR, Malviya S, Voepel-Lewis T, et al. Risk factors for perioperative adverse respiratory events in children with upper respiratory tract infections. Anesthesiology 2001; 95:299.

25. Olsson GL:Bronchosasm during anesthesia.a computer aided incidence study of 136,929 patients.Acta Anaesthesiol Scand 1987;31:244-52.

26. Flick, R., et al., Risk factors for laryngospasm in children during general anesthesia. Paediatr Anaesth, 2008 18(4): p. 289-96.

27. Tait, A. and P. Knight, The effects of general anesthesia on upper respiratory tract infections in children. Anesthesiology. , 1987 67(6): p. 930-5.

28. Tait AR,Knight PR:The effects of general anesthesia on upper respiratory tract infection in children.ANESTHESIOLOGY 1987;67:930-5.

29. Fick RP, Wilder RT, Pieper SF, et al. Risk factors for laryngospasm in children during general anesthesia. Pediatr Anesth. 2008;18(4):289-296.

30. Fisher D, Robinson S. Comparison of enflurane, halothane and isoflurane for diagnostic and therapeutic procedures in children with malignancies.Anesthesiology. 1985;63:647-50.

31. Raylene, D., et al., Critical incidents in paediatric anaesthesia: A prospective analysis over a 1 year period. Indian $\mathrm{J}$ Anaesth, 2016. 60(11): p. 801-806.

32. Alalami , A., C. Ayoub, and A. Baraka, Laryngospasm:review of different prevention and treatement modalities. pediatr Anaesth,, 2008. 18: p. 281-8.

33. Hernández-Cortez E. Update on the management of laryngospasm. J Anesth Crit Care Open Access. 2018;8(2):1-6.

\section{Tables}

Table 1: Surgical and anesthetic related variables of pediatric patients who undergone surgery under GA in UOGCSH, February 1 to August 1, $2019(\mathrm{~N}=310)$. 


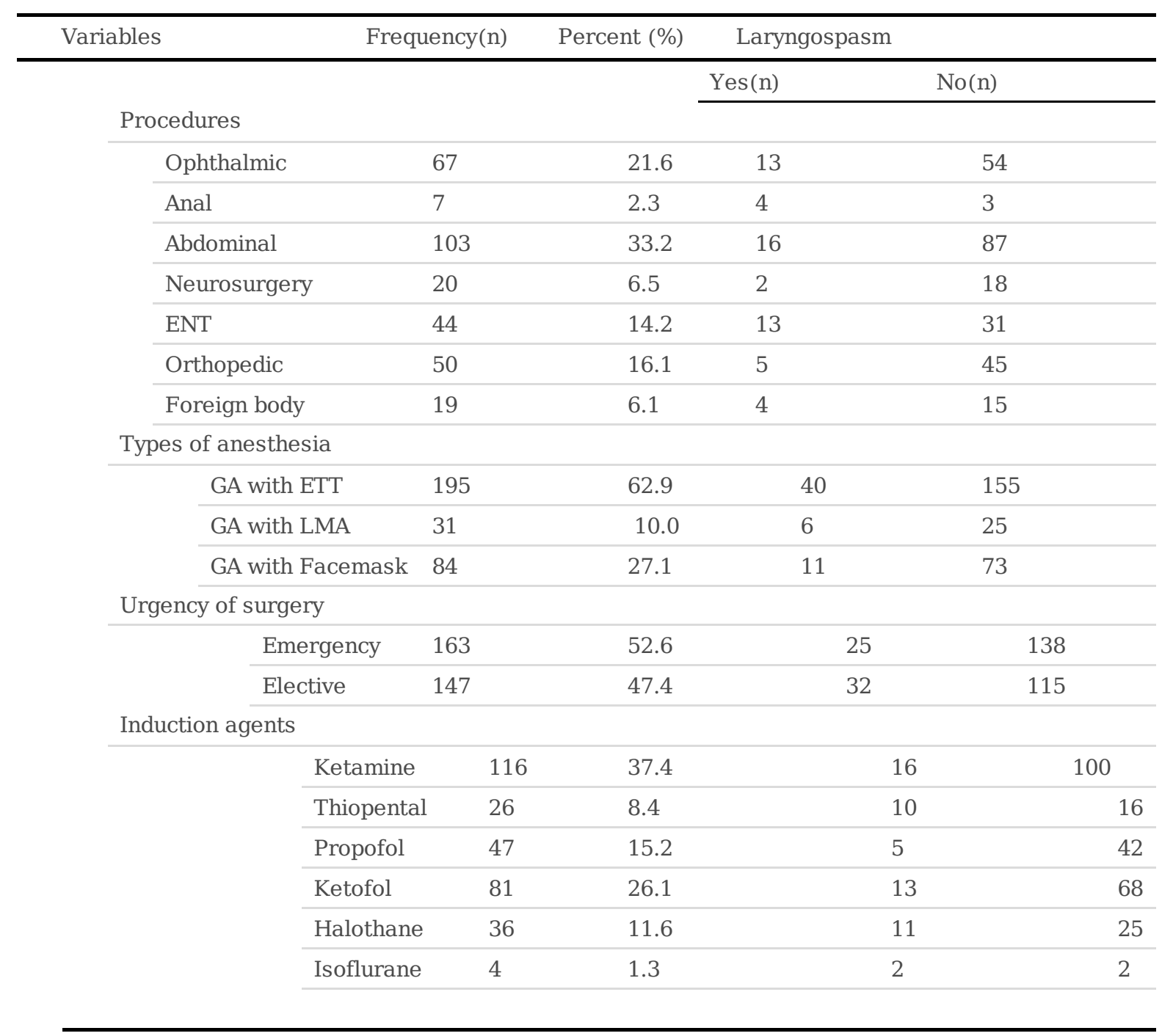

Table 2: Anesthetic related variables of pediatric patients who undergone surgery under GA in UOGCSH, February 1 to August 1, $2019(\mathrm{~N}=310)$. 


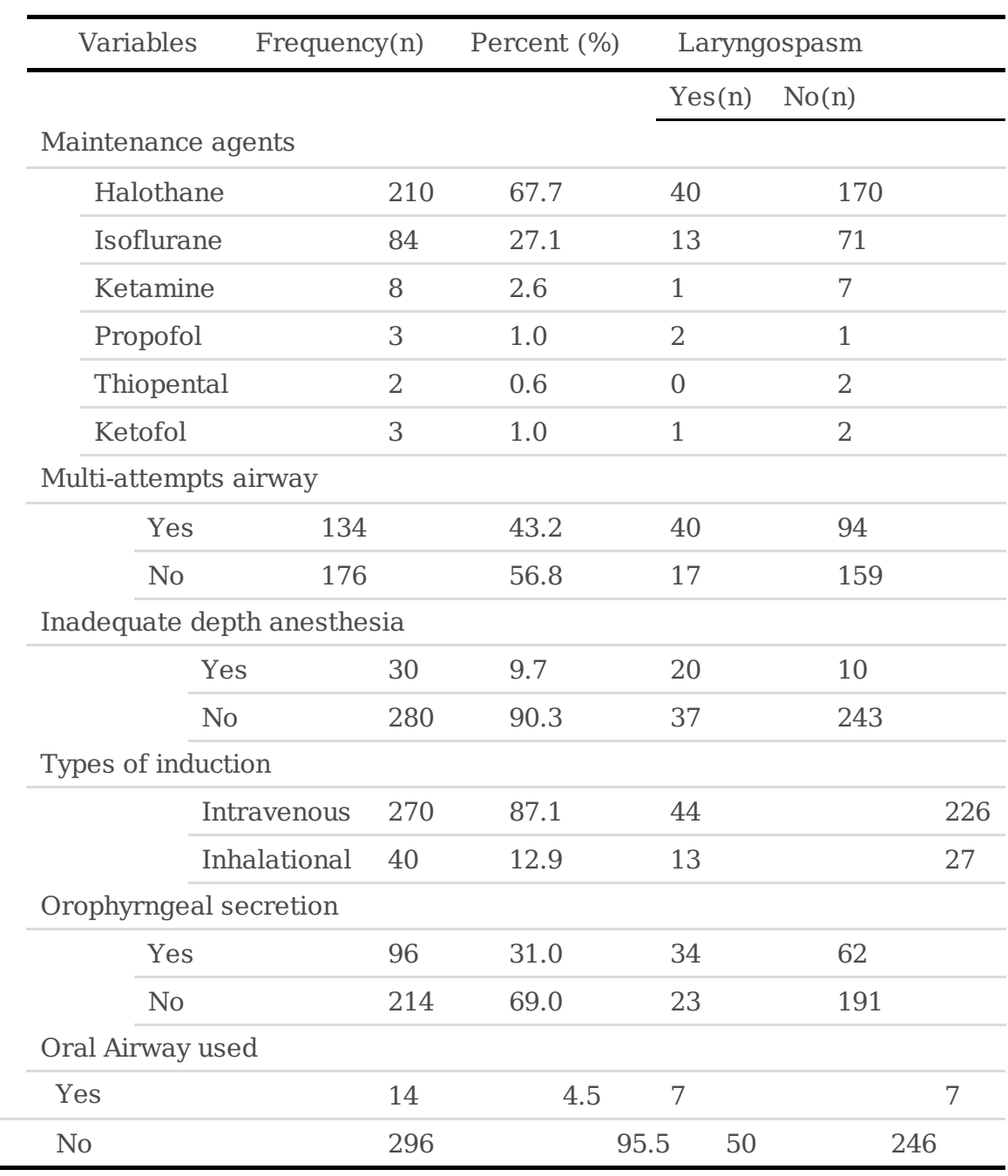

Table 3: Factors fitted into the multivariable logistic regression analysis in pediatric patients who undergone surgery under GA in UOGCSH, February 1 to August 1, 2019(N=310). 


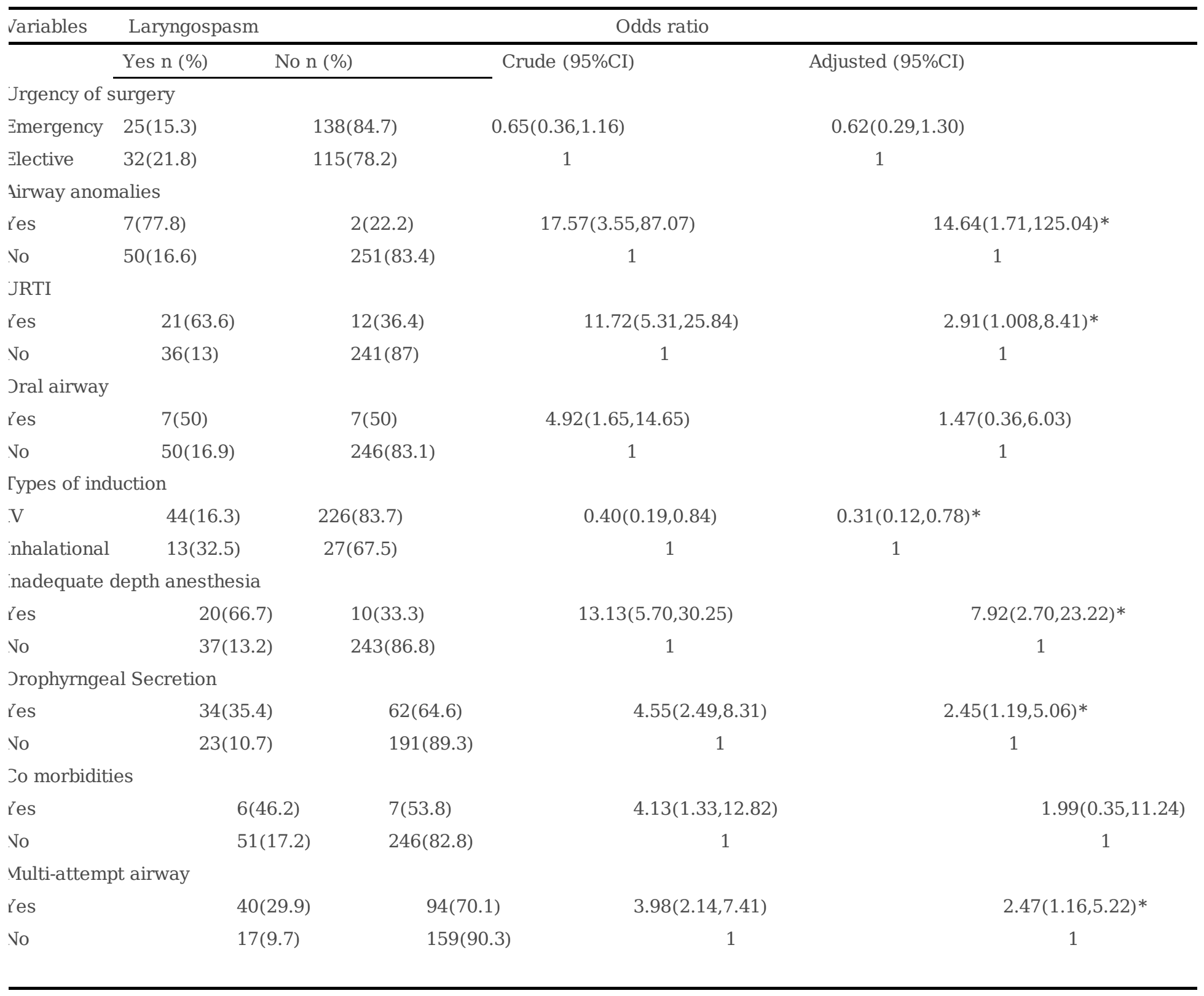

Note- $*$ P-value $<0.05$ was considered as statistically significant 